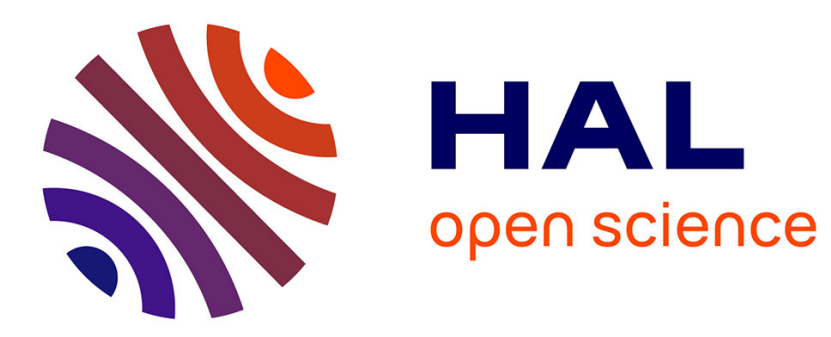

\title{
Bone disorders associated with diabetes mellitus and its treatments
}

Bernard Cortet, Stéphanie Lucas, Isabelle Legroux-Gerot, Guillaume Penel, Christophe Chauveau, Julien Paccou

\section{- To cite this version:}

Bernard Cortet, Stéphanie Lucas, Isabelle Legroux-Gerot, Guillaume Penel, Christophe Chauveau, et al. Bone disorders associated with diabetes mellitus and its treatments. Joint Bone Spine, 2019, 86 (3), pp.315 - 320. 10.1016/j.jbspin.2018.08.002 . hal-03484396

\section{HAL Id: hal-03484396 https://hal.science/hal-03484396}

Submitted on 20 Dec 2021

HAL is a multi-disciplinary open access archive for the deposit and dissemination of scientific research documents, whether they are published or not. The documents may come from teaching and research institutions in France or abroad, or from public or private research centers.
L'archive ouverte pluridisciplinaire HAL, est destinée au dépôt et à la diffusion de documents scientifiques de niveau recherche, publiés ou non, émanant des établissements d'enseignement et de recherche français ou étrangers, des laboratoires publics ou privés.

\section{다)(1) $(5$}

Distributed under a Creative Commons Attribution - NonCommerciall 4.0 International 


\section{Bone Disorders Associated with Diabetes Mellitus and Its Treatments}

Bernard Cortet ${ }^{1,2}$, Stéphanie Lucas ${ }^{2}$, Isabelle Legroux-Gerot ${ }^{1,2}$, Guillaume Penel ${ }^{2,3}$, Christophe Chauveau ${ }^{2}$, Julien Paccou ${ }^{1,2}$

${ }^{1}$ Service de Rhumatologie, CHU de Lille, 59000 Lille, France

${ }^{2}$ Université Lille, Université Littoral Côte d’Opale, EA4490 -PMOI- physiopathologie des maladies osseuses inflammatoires, 59000 Lille, France

${ }^{3}$ Service d'odontologie, CHU de Lille, 59000 Lille, France

Corresponding author: Bernard Cortet, centre de consultation et d'imagerie de l'appareil locomoteur, CHU Lille, 2 avenue Oscar Lambret, 59037 Lille cedex, FRANCE

Tel.: +33 320444037

Fax: +33 320446110

E-mail: bernard.cortet@chru-lille.fr 


\section{ABSTRACT}

Both type 1 and type 2 diabetes mellitus are associated with bone disorders, albeit via different mechanisms. Early studies in patients with type 1 diabetes suggested a 10-fold increase in the hip fracture risk compared to nondiabetic controls. Metaanalyses published more recently indicate a somewhat smaller risk increase, with odds ratios of 6 to 7 .

Diminished bone mineral density is among the contributors to the increased fracture risk. Both types of diabetes are associated with decreased bone strength related to low bone turnover. The multiple and interconnected pathophysiological mechanisms underlying the bone disorders seen in type 1 diabetes include insulin deficiency, accumulation of advanced glycation end products, bone microarchitecture alterations, changes in bone marrow fat content, low-grade inflammation, and osteocyte dysfunction.

The bone alterations are less severe in type 2 diabetes. Odds ratios for hip fractures have ranged across studies from 1.2 to 1.7 , and bone mineral density is higher than in nondiabetic controls. The odds ratio is about 1.2 for all bone fragility fractures combined. The pathophysiological mechanisms are complex, particularly as obesity is very common in patients with type 2 diabetes and is itself associated with an increased risk of fractures at specific sites (humerus, tibia, and ankle). The main mechanisms underlying the bone fragility are an increase in the risk of falls, sarcopenia, disorders of carbohydrate metabolism, vitamin D deficiency, and alterations in cortical bone microarchitecture and bone matrix.

The medications used to treat both types of diabetes do not seem to play a major role. Nevertheless, thiazolidinediones and, to a lesser extent, sodium-glucose cotransporter inhibitors may have adverse effects on bone, whereas metformin may have beneficial effects. 
For the most part, the standard management of bone fragility applies to patients with diabetes. However, emphasis should be placed on preventing falls, which are particularly common in this population. Finally, there is some evidence to suggest that anti-fracture treatments are similarly effective in patients with and without diabetes.

Keywords: Diabetes. Bone fragility. Osteoporosis. Fractures. Hip fractures. Antidiabetic medications. 


\section{Introduction}

Diabetes has adverse effects on bone that translate into an increased fracture risk. However, the mechanisms underlying the bone alterations differ markedly between type 1 and type 2 diabetes.Type 1 diabetes (T1D) affects bone more severely and via a simpler pathophysiological mechanism dependent on a decrease in bone mineral density (BMD). T1D usually starts during adolescence, at a time of accelerated skeletal growth. As a result, the bone becomes compromised at a younger age, and the adverse consequences are even more severe during the aging process. On the other hand, both the incidence and the prevalence of T1D are lower than those of type 2 diabetes (T2D).

That T2D may adversely affect bone health was suggested more recently. The pathophysiology of the bone effects is more complex, in particular because T2D is often combined with obesity, which can also have detrimental effects on bone. In addition, BMD is variably elevated in T2D, an effect that would be expected to increase bone strength. Given these data, we will consider the bone effects of T1D and T2D separately in this review. However, the potential role for anti-diabetic medications in bone disorders will be discussed for both types of diabetes simultaneously.Few data are available on the management of bone fragility in patients with diabetes. Overall, there are only a few differences from the standard treatment of bone fragility.

\section{Effects of type 1 diabetes (t1d) on bone}

That T1D is associated with bone disorders was demonstrated many decades ago. Thus, as early as 1934 several cases of vertebral fracture were reported in patients with 
diabetes [1]. Autopsy data confirmed the association a few years later by showing greater severity of osteoporosis in patients with T1D compared to controls without diabetes [2]. Cohort studies were then carried out. Among them, a study from Israel found that the proportion of patients with diabetes who had at least one vertebral fracture was $20 \%$, which was far higher than expected [3]. The development of BMD measurement techniques, i.e., single-energy then dual-energy X-ray absorptiometry, demonstrated that BMD values in patients with T1D were $30 \%$ to $50 \%$ lower than in non-diabetic controls $[4,5]$.

\subsection{Fracture risk in type 1 diabetes (T1D)}

Several studies showed abnormal bone fragility in patients with T1D [1, 2]. However, only several years after the publication of these studies was clear evidence of an increased fracture risk obtained. For instance, in an 11-year study in 32089 postmenopausal women in Iowa, the hip fracture risk was increased 12-fold in participants with versus without T1D [6]. The risk of hip fracture may be even greater in males. Thus, a study from Norway in 25159 males and females showed that males with T1D had a nearly 18 -fold increase in the hip fracture risk compared to male controls without diabetes [7]. T1D was associated with a 6- to 7-fold increase in the hip fracture risk in two metaanalyses published in 2007 [8, 9]. The risk increase was smaller for vertebral fractures, with an odds ratio (OR) of 2.5 (95\% confidence interval [95\% CI], 1.3-4.6) [10].

More recently, studies have confirmed that the fracture risk is increased in T1D, albeit to a lesser extent than suggested earlier. According to a 2015 metaanalysis, the risk of any fracture was increased 3-fold and the risk of hip fracture in women 5-fold in patients with T1D [11]. These apparent discrepancies may be related to differences in study populations regarding age at cohort inclusion, ethnicity, diabetes duration, and the prevalence of diabetic complications. Furthermore, improvements in T1D management over time may have 
contributed to diminish the fracture risk. In general, and without entering into the pathophysiological considerations that are detailed below, several factors play a key role in the increased fracture risk, notably disease duration and quality of glycemic control [6]. In addition, conflicting data have been reported [12]. Finally, diabetic complications, notably those affecting the microvasculature, undeniably contribute to the fracture risk $[6,9,10]$.

\subsection{Bone mineral density (BMD) in patients with type 1 diabetes (T1D)}

In most studies, patients with T1D had variable decreases in BMD at the spine, hip, and whole body compared to controls [13-17]. Nevertheless, a few studies found no BMD decrease $[18,19]$. Furthermore, the magnitude of the BMD decrease varied considerably across studies, from $8 \%$ to $67 \%$. In a 2007 metaanalysis, the mean BMD decreases were $22 \%$ at the spine and $37 \%$ at the hip compared to age- and sex-matched controls [8]. As with the fracture risk increase, the magnitude of the BMD decline increased with disease duration in most studies. However, the same metaanalysis found no association between the glycated hemoglobin level (Hb1 Ac) and BMD [8]. In general, achieving good glycemic control does not seem sufficient to prevent the BMD decline. As with fractures, diabetic microvascular disease is associated with aggravated bone loss [13-17]. Most of the current data indicate that the BMD decline is not the only contributor to the increased fracture risk and that bone quality is also adversely affected in T1D (see below).

\subsection{Bone microarchitecture in type 1 diabetes (T1D)}

A few studies used high-resolution peripheral quantitative computed tomography (HRpQCT) to assess bone quality in T1D. Compared to controls, patients with T1D had lower total and trabecular volumetric BMD values at the ultradistal radius and tibia, and the differences were greatest in the patients with microvascular disease [20]. Thinning of the 
bone trabeculae and tibial cortex was also most marked in the group with microvascular disease [20]. However, and in contrast to observations often made in T2D, cortical porosity was not increased, even in the patients with microvascular disease.

\subsection{Bone turnover in patients with type 1 diabetes (T1D)}

An association of T1D with decreased bone turnover has been suggested by numerous animal studies $[21,22]$. Osteoblasts and mineralization seem consistently decreased in rodent models. The data on osteoclastogenesis and bone resorption, in contrast, vary somewhat across studies [21, 22].Studies based on bone turnover markers have confirmed these findings in humans [23-25]. Thus, osteocalcin levels seem to be depressed in patients with T1D $[23,24]$. Furthermore, children and young adults with T1D may have abnormally low levels of procollagen type 1 amino-terminal propeptide (P1NP) [25]. However, these data may be biased due to the collagen reticulation alterations seen in T1D, which result in underestimation of levels of carboxy-terminal collagen crosslinks (CTX). Few histological and histomorphometric data are available [26]. Given this caveat, the above-mentioned study supports a substantial decrease in bone formation. A more recent bone-biopsy study demonstrated increases in mineralization and collagen cross-links independent from enzyme activity in patients with T1D, notably those with a history of fractures, compared to nondiabetic controls [27]. These findings therefore also support a decrease in bone turnover. Taken in concert, these data support the existence in T1D of bone quality alterations (affecting bone microarchitecture, bone turnover, and molecular structure) that decrease bone hardness and resistance to mechanical loads. 
Figure 1 recapitulates the cellular and molecular mechanisms involved in the pathophysiology of bone disorders associated with T1D. A few factors may be directly involved in the quantitative and qualitative bone alterations.

\subsubsection{Insulin, incretins}

Insulin has anabolic effects on bone in vitro [28, 29]. In animals with diabetes, insulin treatment corrects the bone-turnover abnormalities and improves some of the bone-quality parameters, depending on the insulin dose and time to insulin initiation [30]. However, insulin deficiency is not the only factor involved in the bone disorders seen in T1D. Insulinlike growth factor 1 (IGF1, also known as somatomedin) plays a pivotal role in bone mass accumulation and maintenance. Depressed IGF1 levels have been reported in T1D and may, per se, contribute to the bone demineralization $[31,32]$.

The main incretins are glucose-dependent insulinotropic peptide (GIP), also known as gastric inhibitory polypeptide, and glucagon-like peptide-1 (GLP-1). Both are hormones that are released by the gastrointestinal tract and potentiate the effect of insulin on carbohydrate metabolism. When evaluating bone disorders, their role seems far greater in T2D than in T1D. Thus, the GLP-1 agonists and dipeptidyl peptidase-4 (DDP-4) inhibitors used to treat T2D may exert substantial effects on bone (see below). In murine models of T1D, incretins can prevent bone microarchitecture alterations and preserve bone quality [33].

\subsubsection{Hyperglycemia and advanced glycation end products (AGEs)}

Hyperglycemia per se suppresses osteoblast differentiation and contributes to the signaling process involved in altering bone formation. Furthermore, chronic hyperglycemia results in nonenzymatic glycation of proteins, notably collagen, leading to increased levels of advanced glycation end products (AGEs). 
AGEs and their receptors are involved in the development of many diabetic complications, including bone alterations. AGEs can affect bonds within the type 1 collagen triple helix, thereby causing alterations in intrinsic bone quality, of which one effect is increased bone rigidity. Pentosidine is the most extensively studied AGE. In a crosssectional study, serum pentosidine levels were elevated in patients with T1D [34], although the large standard deviation warrants circumspection in interpreting this result.

\subsubsection{Bone-marrow fat content}

Bone marrow contains an abundance of stem cells that can differentiate into osteoblasts, adipocytes, or chondrocytes. The development of bone-marrow adipocytes is generating growing interest as a possible explanation to the bone loss seen in T1D. Thus, the bone-marrow fat content correlates negatively with BMD. An increase in bone-marrow fat content at the lumbar spine may be associated with a higher fracture risk in the general population.Stem-cell differentiation to adipocytes involves the transcription factor known as peroxisome proliferator-activated receptor (PPAR $\gamma 2)$ and is viewed as competing with osteoblastogenesis. The above-mentioned decrease in osteoblastogenesis in T1D has therefore turned research attention toward the development of bone-marrow fat. In various murine T1D models, increased PPAR $\gamma 2$ levels and adipocyte counts were found in bone marrow; nevertheless, whether bone loss and increased bone-marrow fat content are linked in this setting has not been proven $[35,36]$. Only limited data are available. Thus, whether fat accumulation within the bone marrow may explain the bone disorders seen in T1D remains to be investigated.

\subsubsection{Inflammation}


Low-grade inflammation is common in patients with T2D. However, T1D is also associated with overexpression of the main genes involved in inflammatory processes. Similarly, diabetic complications, notably microvascular disease, are partly related to inflammatory alterations. Additional data are needed to further evaluate this hypothesis in T1D.

\subsubsection{Disorders in osteocyte function}

As indicated above, osteoblast suppression may be a major factor in the genesis of bone disorders associated with T1D. Data also suggest alterations in osteocyte function involving sclerostin, a Wnt-pathway inhibiting factor released by osteocytes. The Wnt pathway is crucial to osteoblast differentiation. Elevated sclerostin levels have been reported in patients with T1D [34]. The duration of T1D may influence the sclerostin levels.

\section{Effects of type 2 diabetes $(\mathrm{t} 2 \mathrm{~d})$ on bone}

T2D is far more common than T1D. The number of patients with T2D is currently estimated at 422 million worldwide [37]. The T2D/T1D ratio is $0.9 / 0.1$. In addition, the incidence of T2D has been climbing steadily in recent years, in large part due to the obesity epidemic. The mechanisms underlying the increased fracture risk are more complex in T2D than in T1D. In particular, BMD values, which are usually low in patients with T1D, are generally elevated in those with T2D.

\subsection{Epidemiology}

A fracture risk increase was demonstrated by several studies of patients with T2D. Overall, the risk increase is smaller than in T1D (Table 1). That the hip fracture risk is 
elevated has been convincingly demonstrated, with ORs ranging across studies from 1.2 to $1.7[8,9,37-41]$. Although the results vary somewhat, both longer diabetes duration and poor glycemic control seem associated with a higher fracture risk [42].

\subsection{Pathophysiology of bone disorders in type 2 diabetes (T2D)}

The fracture risk increase involves many causes or risk factors, which are more or less interconnected and differ in part from those relevant to T1D. As most studies showed no decline in BMD values, the increased bone fragility is strongly believed to be related to alterations in bone quality.

\subsubsection{Obesity}

Higher body weight protects against bone loss up to a certain point. However, the relation is not linear. Thus, when body mass index (BMI) values enter the overweight zone, i.e., become greater than $25 \mathrm{~kg} / \mathrm{m}^{2}$, no further bone protection occurs with additional weight gain. In addition, patients with obesity are at increased risk for fractures at certain sites such as the humerus, leg, and ankle [43]. Given that many patients with T2D are also obese, the relative contributions of the two diseases may be difficult to tease apart.

\subsubsection{Increased fall risk}

An increased risk of falls has been demonstrated both in patients with T2D and in those with obesity [44]. The increase is multifactorial and involves visual loss due to cataract and retinopathy, cardiac arrhythmias, neuropathy, hypoglycemia, and other factors.

\subsubsection{Sarcopenia}


Sarcopenia increases the risk of falls in the general population. This effect seems particularly marked in patients with diabetes, particularly those who are also obese (sarcopenic obesity). In patients with diabetes, sarcopenia seems independent from the presence of neuropathy [45].

\subsubsection{Alterations in carbohydrate metabolism}

T2D is characterized by insulin resistance. There is sound evidence that insulin metabolism abnormalities influence bone turnover (see below). Furthermore, hyperglycemia leads to AGE accumulation within the bone matrix. The build-up of AGEs also contributes to alter bone tissue quality [46].

\subsubsection{Vitamin D deficiency}

Vitamin D deficiency is more marked in patients with T2D than in the general population. One contributor to this difference is obesity. In addition to its effects on bone, vitamin D may participate in maintaining glycemic control, as the pancreatic beta cells carry vitamin D receptors. However, vitamin D supplementation seems to have no effect on glycemic control [42].

\subsubsection{Bone turnover}

Few histomorphometric data from patients with T2D are available. In a study of 26 patients, decreases were found in osteoid thickness, osteoid volume, and osteoblast surface area compared to age-matched controls without diabetes [47]. Other studies suggest decreases in dynamic parameters associated with the level of bone turnover such as the bone formation rate, mineralized surface area, and bone mineralization rate. In keeping with these 
data, there is an overall decrease in bone turnover markers including CTX and osteocalcin [48].

\subsubsection{Alterations in bone microarchitecture}

HR-pQCT has been used to investigate bone microarchitecture in T2D [49-51], with conflicting results. One study, in only 19 patients with T2D, showed increased cortical porosity at the radius and tibia compared to healthy controls [49]. A larger study in 190 males with T2D demonstrated a decrease in total bone surface area at the radius and tibia combined with a decrease in bone strength (evaluated using the finite element method) confined to the cortices of these two bones [50]. Another study compared postmenopausal women with and without diabetes [51]. In both groups, some patients had a history of fractures. Within the T2D group, patients with fractures had moderate alterations in cortical bone microarchitecture, with an increase in cortical porosity, compared to those without fractures. Interestingly, no such difference was found between non-diabetic patients with versus without fractures. A more recent study used HR-pQCT to investigate 1069 males and females, among whom $12 \%$ had T2D [52]. After adjustments on multiple factors, T2D was associated with decreases in cortical bone density and tibial bone surface area and with an increase in cortical porosity. However, the differences were moderate. Furthermore, the trabecular parameters were better in the patients with than without diabetes. Patients with diabetes and a history of fracture had lower values of tibial volumetric BMD and radial cortical thickness [52].Some of the data are conflicting, however. In a small study of 25 individuals, HR-pQCT parameters failed to demonstrate any differences between patients with T2D and controls. Other studies also showed no differences in bone microarchitecture and bone strength parameters between women with and without T2D [54, 55]. 
The trabecular bone score (TBS) has been the focus of a few studies [56, 57]. The results suggest that TBS values may be lower in patients with T2D, although their BMD values are usually elevated. These results may seem surprising since both the TBS and BMD are measured at the lumbar spine based on the same acquisitions.

\subsubsection{Microindentation}

Bone microindentation testing is a recently developed tool for measuring the resistance of subperiosteal bone to penetration at the proximal tibia. A probe is applied, and the depth of the indentation thus produced is then measured and used to determine the bone material strength index (BMSi), which reflects bone strength. The BMSi is decreased in patients with bone fragility, due for instance to postmenopausal osteoporosis. In addition, the results obtained using microindentation may be partly independent from the BMD values. Although the studies done so far in T2D involved only small numbers of patients, their results suggest a decrease in the BMSi $[54,55,58]$. In the earliest study, BMSi was significantly lower in 30 patients with T2D than in 30 controls. Furthermore, HbA1c values correlated negatively with the BMSi. Similar results have been obtained in larger studies $[55,58]$.

\subsubsection{Bone matrix alterations: role for advanced glycation end products}

(AGEs)

As indicated above, AGEs include several groups of compounds produced by nonenzymatic glycation of various proteins (including type 1 collagen). AGEs inhibit osteoblastic differentiation. The build-up of AGEs within the bone matrix alters the biomechanical properties of bone. AGE levels are elevated in patients with T2D [59]. Thus, a role for AGEs in the bone disorders associated with T2D is a plausible pathogenic hypothesis that deserves further investigation. 


\section{Effects of anti-diabetic medications on bone tissue}

Overall, data are scant. Table 2 reports the main available evidence. It is worth noting that the medications listed in Table 2 are not, or no longer, reimbursed by the French statutory healthcare system. Thus, thiazolidinediones are no longer reimbursed and sodiumglucose cotransporter inhibitors have never been reimbursed.Hypoglycemic sulfonamides have no direct effect on bone (Table 2). However, they may increase the fall risk by causing hypoglycemic episodes. In vitro data on metformin suggest a protective effect on bone, but studies in humans are less conclusive [60]. Thiazolidinediones activate PPAR $\gamma$, thereby adversely affecting bone and increasing the fracture risk [61, 62]. As mentioned above, thiazolidinediones are no longer available in France. Incretins seem to protect bone in vitro, but their in vivo effects are more difficult to interpret [63-65]. Among the sodium-glucose cotransporter inhibitors, canagliflozine may exert deleterious effects on bone, causing an increase in the fracture risk $[66,67]$. This drug class is not reimbursed in France.

\section{Management of bone disorders in patients with type 1 or}

\section{2 diabetes}

Very few data specific of patients with T1D or T2D are available. Therefore, the measures are derived from common sense rather than from scientific evidence. In general, fall prevention is important, as falls are common in patients with either type of diabetes. Preventing hypoglycemic episodes is a major factor in avoiding falls. Weight loss is a key priority in patients with T2D, since obesity is an independent risk factor for falls. Bariatric 
surgery has been proven beneficial in patients with severe T2D. However, the welldocumented adverse effects of the procedure on bone require close monitoring and appropriate vitamin D supplementation, as the malabsorption induced by the procedure promotes vitamin D deficiency. Data are extremely scant on the use of osteoporosis medications in patients with diabetes. Post hoc analyses of data from the main pivotal trials of alendronate and raloxifene suggest comparable BMD gains with both drugs in patients with and without diabetes $[68,69]$. Similarly, in a nationwide registry study from Denmark, bisphosphonates and raloxifene were similarly effective in preventing fractures in patients with T1D, patients with T2D, and patients without diabetes [70]. Finally, a post hoc analysis of data from the DANCE study of teriparatide suggested similar antifracture effects in patients with and without diabetes [71].

In conclusion, both T1D and T2D are associated with bone fragility, although the underlying mechanisms differ. The pathophysiological mechanisms responsible for bone alterations are less complex in T1D than in T2D. In T1D, the insulin deficiency combined with many other factors lead to a decrease in BMD values and to alterations in bone quality. The situation is more complex in $\mathrm{T} 2 \mathrm{D}$, as $\mathrm{BMD}$ is elevated and the bone quality alterations are multifactorial. The contribution of anti-diabetic medications, if any exists, seems limited, except perhaps via the induction of hypoglycemic episodes responsible for falls. Finally, data are scarce on the management of bone fragility in patients with diabetes. Consequently, common-sense measures should be applied, with special attention to fall prevention. The few available data suggest that osteoporosis medications are similarly effective in patients with and without diabetes.

\section{Disclosure of interests}


B Cortet has received honoraria or fees in the framework of research contrasts with Amgen, Expanscience, Ferring, Lilly, Medtronic, MSD, Mylan, Novartis, Roche Diagnostics, and UCB.

Stéphanie Lucas has no conflicts of interest to declare.

I Legroux-Gérot has received honoraria or fees in the framework of research contrasts with Amgen and Lilly.

Guillaume Penel has no conflicts of interest to declare.

Christophe Chauveau has no conflicts of interest to declare.

J Paccou has received honoraria or fees in the framework of research contrasts with Amgen, Lilly, Novartis, MSD, Janssen, and UCB. 


\section{References}

[1] Root HF, White P, Marble A. Abnormalities of calcium deposition in diabetes mellitus. Arch Intern Med 1934; 53:46-52.

[2] Hernberg CA. Skeletal variations in adults with diabetes mellitus. Acta Med Scand $1952 ; 143: 1-14$

[3] Menczel J, Makin M, Robin G et al. Prevalence of diabetes mellitus in 451 Jerusalem; its association with presenile osteoporosis. Isr J Med Sci 1972; 8:918-9. [4] Levin ME, Boisseau VC, Avioli LV. Effects of diabetes mellitus on bone mass in 455 juvenile and adult-onset diabetes. N Engl J Med 1976; 294: 241-5.

[5] McNair P, Madsbad S, Christensen MS et al. Bone mineral loss in insulin-treated diabetes mellitus: studies on pathogenesis. Acta Endocrinol [Copenh] 1979; 90:463-72. [6] Nicodemus KK, Folsom AR. Type 1 and type 2 diabetes and incident hip fractures in postmenopausal women. Diabetes Care 2001; 24:1192-7.

[7] Ahmed LA, Joakimsen RM, Berntsen GK et al. Diabetes mellitus and the risk of nonvertebral fractures: the Tromso study. Osteoporos Int 2006; 17:495-500.

[8] Vestergaard P. Discrepancies in bone mineral density and fracture risk in patients with type 1 and type 2 diabetes-a meta-analysis. Osteoporos Int 2007;18:427-44.

[9] Janghorbani M, Van Dam RM, Willett WC et al. Systematic review of type 1 and type 2 diabetes mellitus and risk of fracture. Am J Epidemiol 2007; 166: 495-505.

[10] Vestergaard P, Rejnmark L; Mosekilde L. Relative fracture risk in patients with diabetes mellitus, and the impact of insulin and oral antidiabetic medication on relative fracture risk. Diabetologia 2005; 48:1292-9.

[11] Shah VN, Shah CS , Snell-Bergeon JK. Type 1 diabetes and risk of fracture: metaanalysis and review of the literature. Diabet Med 2015; 32:1134-42. 
[12] Neumann T, Samann A, Lodes S, et al. Glycaemic control is positively associated with prevalent fractures but not with bone mineral density in patients with Type 1 diabetes. Diabet Med 2011;28:872-5.

[13] Eller-Vainicher C, Zhukouskaya VV, Tolkachev YV et al. Low bone mineral density and its predictors in type 1 diabetic patients evaluated by the classic statistics and artificial neural network analysis. Diabetes Care 2011;34: 2186-91.

[14] Heilman K, Zilmer M, Zilmer K et al. Lower bone mineral density in children with type 1 diabetes is associated with poor glycemic control and higher serum ICAM-1 and urinary isoprostane levels. J Bone Miner Metab 2009;27:598-604.

[15] Kemink SA, Hermus AR, Swinkels LM et al. Osteopenia in insulin-dependent diabetes mellitus; prevalence and aspects of pathophysiology. J Endocrinol Invest 2000;23:295-303.

[16] Lopez-Ibarra PJ, Pastor MM, Escobar-Jimenez F et al. Bone mineral density at time of clinical diagnosis of adult-onset type 1 diabetes mellitus. Endocr Pract 2001;7:346-51.

[17] Rakic V, Davis WA, Chubb SA et al. Bone mineral density and its determinants in diabetes: the Fremantle Diabetes Study. Diabetologia 2006;49:863-71.

[18] Bridges MJ, Moochhala SH, Barbour J et al. Influence of diabetes on peripheral bone mineral density in men: a controlled study. Acta Diabetol 2005;42: 82-86.

[19] Ingberg CM, Palmer M, Aman J et al. Body composition and bone mineral density in long-standing type 1 diabetes. J Intern Med 2004;255:392-8.

[20] Shanbhogue VV, Hansen S, Frost M et al. Bone geometry, volumetric density, microarchitecture, and estimated bone strength assessed by HR-pQCT in adult patients with type 1 diabetes mellitus. J Bone Miner Res 2015; 30:2188-99. 
[21] Hough S, Avioli LV, Bergfeld MA et al. Correction of abnormal bone and mineral metabolism in chronic streptozotocin induced diabetes mellitus in the rat by insulin therapy. Endocrinology 1981;108:2228-34.

[22] Hough S, Fausto A, Sonn Y et al. Vitamin D metabolism in the chronic streptozotocin-induced diabetic rat. Endocrinology 1983;113:790-6.

[23] Lumachi F, Camozzi V, Tombolan V et al. Bone mineral density, osteocalcin, and bone-specific alkaline phosphatase in patients with insulin-dependent diabetes mellitus. Ann N Y Acad Sci 2009;1173 Suppl 1:E64-67.

[24] Maggio AB, Ferrari S, Kraenzlin M et al. Decreased bone turnover in children and adolescents with well controlled type 1 diabetes. J Pediatr Endocrinol Metab 2010; 23:697707.

[25] Abdalrahaman N, McComb C, Foster JE et al. Deficits in trabecular bone microarchitecture in young women with type 1 diabetes mellitus. J Bone Miner Res 2015; 30:1386-1393.

[26] Krakauer JC, McKenna MJ, Buderer NF. Bone loss and bone turnover in diabetes. Diabetes 1995 44: 775-782.

[27] Farlay D, Armas LA, Gineyts et al. Nonenzymatic glycation and degree of mineralization are higher in bone from fractured patients with Type 1 diabetes mellitus. $\mathbf{J}$ Bone Miner Res 2016;31:190-195.

[28] Kream BE, Smith MD, Canalis E et al. Characterization of the effect of insulin on collagen synthesis in fetal rat bone. Endocrinology 1985; 116:296-302.

[29] Akune T, Ogata N, Hoshi K et al. Insulin receptor substrate-2 maintains predominance of anabolic function over catabolic function of osteoblasts. J Cell Biol 2002;159:147-56. 
[30] Verhaeghe J, Suiker AM, Visser WJ. The effects of systemic insulin, insulin-like growth factor-I and growth hormone on bone growth and turnover in spontaneously diabetic BB rats. J Endocrinol 1992; 134:485-92.

[31] Bouillon R, Bex M, Van Herck E et al. Influence of age, sex, and insulin on osteoblast function: osteoblast dysfunction in diabetes mellitus. J Clin Endocrinol Metab 1995;80: 1194-202.

[32] Kemink SA, Hermus AR, Swinkels LM et al. Osteopenia in insulin-dependent diabetes mellitus; prevalence and aspects of pathophysiology. J Endocrinol Invest 2000;23:295-303.

[33] Mansur SA, Mieczkowska A, Bouvard B et al. Stable incretin mimetics counter rapid deterioration of bone quality in type 1 diabetes mellitus. J Cell Physiol 2015;230:3009-18. [34] Neumann T, Lodes S, Kastner B, et al. High serum pentosidine but not esRAGE is associated with prevalent fractures in type 1 diabetes independent of bone mineral density and glycaemic control. Osteoporos Int 2014; 25:1527-1533.

[35] McCabe LR. Understanding the pathology and mechanisms of type I diabetic bone loss. J Cell Biochem 2007;102:1343-1357.

[36] Diascro DD, Jr., Vogel RL, Johnson TE et al. High fatty acid content in rabbit serum is responsible for the differentiation of osteoblasts into adipocyte-like cells. J Bone Miner Res 1998;13:96-106.

[37] World Health Organisation. Diabetes www.who.int/mediacentre/factsheets/fs312/en/ [38] Fan Y, Wei F, Lang Y, Liu Y. Diabetes mellitus and risk of hip fractures: a metaanalysis. Osteoporos Int. 2016;27:219-28.

[39] Wang J, You W, Jing Z et al. Increased risk of vertebral fracture in patients with diabetes: a meta-analysis of cohort studies. Int Orthop 2016;40:1299-307. 

postmenopausal women: meta-analysis of observational studies. Aging Clin Exp Res. 2017;29:301-309.

[41] Moayeri A, Mohamadpour M, Mousavi SF et al. Fracture risk in patients with type 2 diabetes mellitus and possible risk factors: a systematic review and meta-analysis. Ther Clin Risk Manag. 2017;13:455-68.

[42] Compston J. Type 2 diabetes mellitus and bone. J Intern Med. 2018;283:140-153.

[43] Cortet B, Roux C. Obésité et ostéoporose. Revue du rhumatisme monographies 2016;83:25-28.

[44] Herrera-Rangel AB, Aranda-Moreno C, Mantilla-Ochoa T et al. Influence of the body mass index on the occurrence of falls in patients with type 2 diabetes mellitus. Obes Res Clin Pract. 2015;9:522-6.

[45] Volpato S, Bianchi L, Lauretani F, et al. Role of muscle mass and muscle quality in the association between diabetes and gait speed. Diabetes Care. 2012;35:1672-9.

[46] Brownlee M, Cerami A, Vlassara H. Advanced glycosylation end products in tissue and the biochemical basis of diabetic complications. N Engl J Med. 1988 19;318:1315-21. [47] Leite Duarte ME, da Silva RD. Histomorphometric analysis of the bone tissue in patients with non-insulin-dependent diabetes [DMNID]. Rev Hosp Clin Fac Med Sao Paulo $1996 ; 51: 7-11$.

[48] Starup-Linde J, Vestergaard P. Biochemical bone turnover markers in diabetes mellitus - A systematic review. Bone 2016;82:69-78.

[49] Burghardt AJ, Issever AS, Schwartz AV et al. High-resolution peripheral quantitative computed tomographic imaging of cortical and trabecular bone microarchitecture in patients with type 2 diabetes mellitus. J Clin Endocrinol Metab. 2010;95:5045-55. 
[50] Petit MA, Paudel ML, Taylor BC et al; Osteoporotic fractures in men [MrOs] study group. Bone mass and strength in older men with type 2 diabetes: the osteoporotic fractures in men study. J Bone Miner Res. 2010;25:285-91.

[51] Patsch JM, Burghardt AJ, Yap SP et al. Increased cortical porosity in type 2 diabetic postmenopausal women with fragility fractures. Increased cortical porosity in type 2 diabetic postmenopausal women with fragility fractures. J Bone Miner Res. 2013;28:313-24.

[52] Samelson EJ, Demissie S, Cupples LA et al. Diabetes and deficits in cortical bone density, microarchitecture, and bone size: Framingham HR-pQCT Study. J Bone Miner Res. 2018;33:54-62.

[53] Shu A, Yin MT, Stein E et al. Bone structure and turnover in type 2 diabetes mellitus. Osteoporos Int 2012;23:635-41.

[54] Farr JN, Drake MT, Amin S, Melton LJ 3rd, McCready LK, Khosla S. In vivo assessment of bone quality in postmenopausal women with type 2 diabetes. J Bone Miner Res. 2014;29:787-95.

[55] Nilsson AG, Sundh D, Johansson L et al. Type 2 diabetes mellitus Is associated with better bone microarchitecture but lower bone material strength and poorer physical function in elderly women: a population-based study. J Bone Miner Res 2017;32:1062-71.

[56] Dhaliwal R, Cibula D, Ghosh C et al. Bone quality assessment in type 2 diabetes mellitus. Osteoporos Int. 2014;25:1969-73.

[57] Kim JH, Choi HJ, Ku EJ et al. Trabecular bone score as an indicator for skeletal deterioration in diabetes. J Clin Endocrinol Metab. 2015;100:475-82.

[58] Sundh D, Rudäng R, Zoulakis M et al. A High amount of adipose tissue Is associated with high cortical porosity and low bone material strength in older women. J Bone Miner Res. 2016;31:749-57. 
[59] Makita Z, Radoff S, Rayfield EJ et al. Advanced glycosylation end products in patients with diabetic nephropathy. N Engl J Med. 1991;325:836-42.

[60] Vestergaard P, Rejnmark L, Mosekilde L. Relative fracture risk in patients with diabetes mellitus, and the impact of insulin and oral antidiabetic medication on relative fracture risk. Diabetologia 2005; 48:1292-9.

[61] Gimble JM, Robinson CE, Wu X et al. Peroxisome proliferator-activated receptorgamma activation by thiazolidinediones induces adipogenesis in bone marrow stromal cells. Mol Pharmacol. 1996;50:1087-94.

[62] Loke YK, Singh S, Furberg CD. Long-term use of thiazolidinediones and fractures in type 2 diabetes: a meta-analysis. CMAJ 2009;180:32-9.

[63] Su B, Sheng H, Zhang M et al. Risk of bone fractures associated with glucagon-like peptide-1 receptor agonists' treatment: a meta-analysis of randomized controlled trials. Endocrine 2015;48:107-15.

[64] Dombrowski S., Kostev K., Jacob L. Use of dipeptidyl peptidase-4 inhibitors and risk of bone fracture in patients with type 2 diabetes in Germany - a retrospective analysis of real-world data. Osteoporos Int 2017; 29:1-8.

[65] Driessen JH, de Vries F, van Onzenoort $\mathrm{H}$ et al. The use of incretinsisepiand fractures a meta-analysis on population-based real life data. Br J Clin Pharmacol 2017;83:923-6. [66] Watts NB, Bilezikian JP, Usiskin K et al. Effectsisepiof canagliflozin on fracture risk in patients with type 2 diabetes mellitus. J Clin Endocrinol Metab 2016;101:157-66. [67] Ruanpeng D, Ungprasert P, Sangtian J, Harindhanavudhi T. Sodium-glucose cotransporter 2 (SGLT2) inhibitors and fracture risk in patients with type 2 diabetes mellitus: A meta-analysis. Diabetes Metab Res Rev. 2017. doi: 10.1002/dmrr.2903. 
[68] Keegan TH, Schwartz AV, Bauer DC. Fracture Intervention Trial. Effect of alendronate on bone mineral density and biochemical markers of bone turnover in type 2 diabetic women: the Fracture Intervention Trial. Diabetes Care 2004;27:1547-53.

[69] Ensrud KE, Stock JL, Barrett-Connor E, et al. Effects of raloxifene on fracture risk in postmenopausal women: the raloxifene use for the heart trial. J Bone Miner Res 2008;23:112-20.

[70] Vestergaard P, Rejnmark L, Mosekilde L. Are antiresorptive drugs effective against fractures in patients with diabetes? Calcif Tissue Int 2011;88:209-14.

[71] Schwartz AV, Pavo I, Alam J et al. Teriparatide in patients with osteoporosis and type 2 diabetes. Bone. 2016;91:152-8. 
Table 1 : Main data on the fracture risk in patients with type 2 diabetes

\begin{tabular}{|l|l|l|l|}
\hline Authors & Fracture sites & $\begin{array}{l}\text { Odds ratio or } \\
\text { Relative risk }\end{array}$ & 95\%CI \\
\hline Janghorbani 2007 [9] & Hip & 1.7 & {$[1.30-2.20]$} \\
\hline Vestergaard 2007 [8] & Hip, & 1.38 & {$[1.25-1.53]$} \\
\hline Fan 2016 [38] & Hrist & 1.19 & {$[1.10-1.41]$} \\
\hline Wang 2016 [39] & Spine & 1.34 & {$[1.19-1.51]$} \\
\hline Dytfield 2017* [40] & Hip & 2.03 & {$[1.60-2.59]$} \\
\hline & Hip & 1.296 & {$[1.07-1.57]$} \\
\hline Moayeri 2017 [41] & Spine & 1.20 & {$[1.17-1.23]$} \\
& Foot & 1.16 & {$[1.15-1.20]$} \\
\hline
\end{tabular}

*Postmenopausal women 
Table 2: Effects of antidiabetic medications on bone

\begin{tabular}{|c|c|c|c|}
\hline Medication & Mechanism of action & Effect on BMD & $\begin{array}{l}\text { Effect on the } \\
\text { fracture risk }\end{array}$ \\
\hline $\begin{array}{l}\text { Hypoglycemic } \\
\text { sulfonamides [60] }\end{array}$ & $\begin{array}{l}\text { No direct effect on bone } \\
\text { tissue }\end{array}$ & No data & No change \\
\hline Metformin [60] & $\begin{array}{l}\text { Stimulates } \\
\text { osteoblastogenesis and } \\
\text { decreases bone } \\
\text { resorption }\end{array}$ & No change & $\begin{array}{l}\text { Decrease (or no } \\
\text { change) }\end{array}$ \\
\hline $\begin{array}{l}\text { Thiazolidinediones } \\
{[61,62]}\end{array}$ & $\begin{array}{l}\text { Activates PPAR } \gamma \\
\text { (inhibit } \\
\text { osteoblastogenesis and } \\
\text { increase bone } \\
\text { resorption) }\end{array}$ & Decrease & Increase \\
\hline Incretins[63-65] & $\begin{array}{l}\text { Inhibit bone resorption } \\
\text { (preclinical data) }\end{array}$ & No change & $\begin{array}{l}\text { Decrease (or no } \\
\text { change) }\end{array}$ \\
\hline $\begin{array}{l}\text { Sodium-glucose } \\
\text { cotransporter } \\
\text { inhibitors }[66,67]\end{array}$ & $\begin{array}{l}\text { Increase phosphate } \\
\text { reabsorption by the renal } \\
\text { tubule }\end{array}$ & $\begin{array}{l}\text { Decrease } \\
\text { (canagliflozine) }\end{array}$ & $\begin{array}{l}\text { Possible } \\
\text { increase } \\
\text { (canagliflozine) }\end{array}$ \\
\hline
\end{tabular}


Figure 1 : Pathophysiology of bone disorders associated with type 1 diabetes IGF-1, insulin-like growth factor-1; PTH, parathyroid hormone; PGs, prostaglandins; IL, interleukin; TNF, tumor necrosis factor 
Hormonal and metabolic alterations

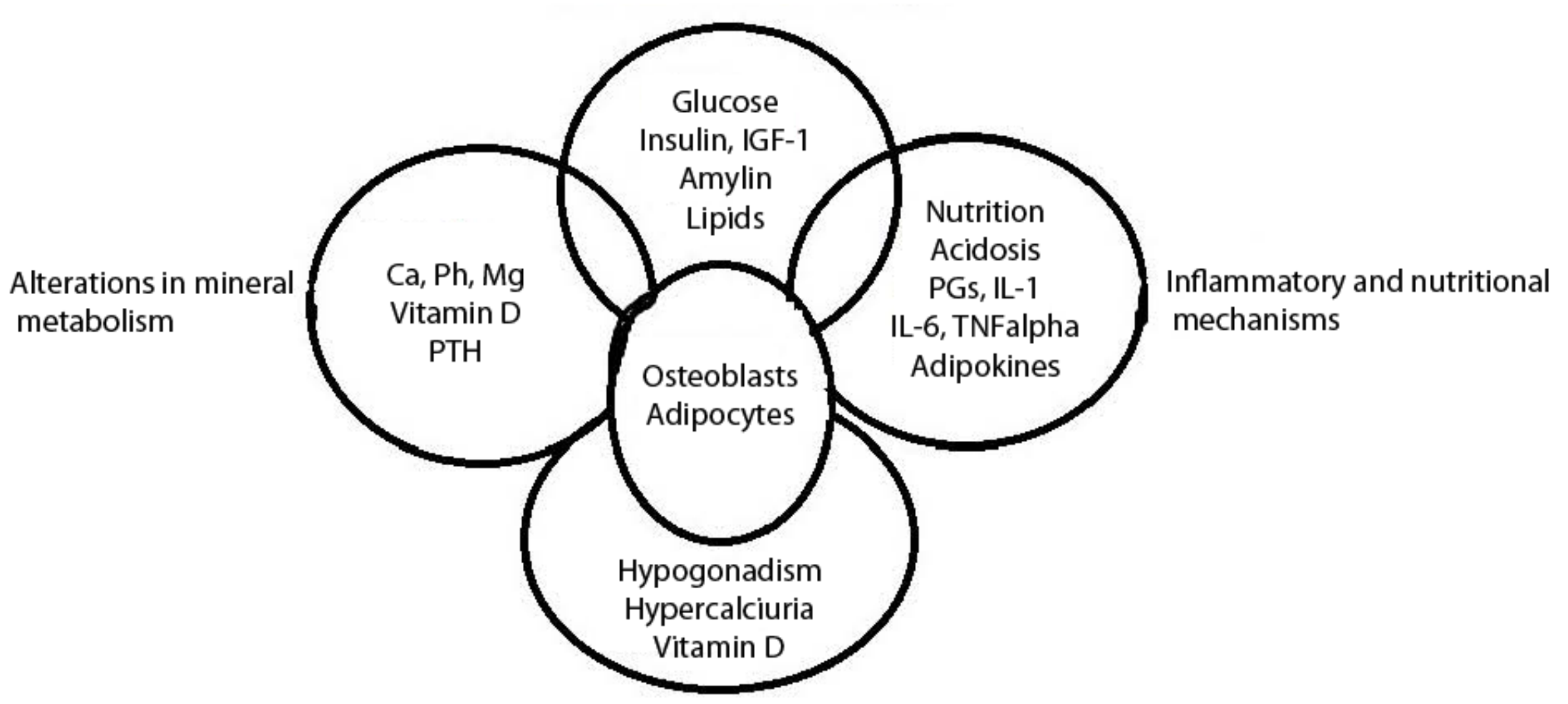

Concomitant disorders 